\title{
Rancang Bangun Mesin Penggembur Tanah Menggunakan Mesin Pemotong Rumput
}

\author{
Sandriyanto Une ${ }^{1)}$, Syamsu Akuba ${ }^{2)}$, Burhan Liputo $^{3)}$ \\ 1,2,3) Program Studi Mesin dan Peralatan Pertanian, Politeknik Gorontalo \\ Jl. Muchlis Rahim, Desa Ponggulo Barat, Kec. Botupingge, Kab. Bone Bolango, Gorontalo, Indonesia \\ e-mail: sandriyantoune@gmail.com
}

\begin{abstract}
ABSTRAK
Pengolahan tanah merupakan kegiatan yang bertujuan untuk mendapatkan kondisi tanah yang baik. Kondisi tanah yang baik dimanfaatkan sebagai media tumbuh bagi berbagai jenis tanaman dan pembangan akarnya. Salah satu indikator tanah yang baik adalah tingkat kesuburannya. Kesuburan tanah adalah kemampuan suatu tanah untuk menyediakan unsur hara bagi tanaman. Beberapa proses yang dapat dilakukan untuk menjaga kesuburan tanah adalah upaya penggemburan tanah. Penggemburan tanah umumnya dilakukan pada lahan-lahan yang kering dan padat dan biasanya petani masih menggunakan alat tradisional untuk mengolah tanah tersebut. Penggunaan alat tradisional tentu akan mengurangi tingkat produktivitas karena memerlukan waktu, tenaga, dan biaya yang cukup tinggi. Oleh karena itu, perlu adanya alat atau mesin yang dapat digunakan untuk mengganti alat-alat tradisional tersebut. Tujuan dari penelitian ini adalah merancang mesin penggembur tanah dengan memanfaatkan mesin potong rumput sebagai motor penggerak. Mesin ini dilengkapi dengan bajak singkal dan bajak rotary. Pengujian mesin dilakukan pada lahan kering dengan luasan $30 \mathrm{~m}^{2}$. Berdasarkan hasil penelitian dan pengujian diketahui bahwa mesin penggembur tanah dengan motor penggerak mesin potong rumput memiliki kinerja sekitar $0,115 \mathrm{~m}^{2} /$ detik atau setara dengan $414 \mathrm{~m}^{2} / \mathrm{jam}$. Kinerja mesin masih tergolong kecil karena beberapa faktor diantaranya dimensi bajak rotary yang kecil dan putaran yang terlalu cepat. Oleh karena itu, perlu adanya modifikasi dan pengembangan yang lebih optimal sehingga mesin ini diharapkan dapat dimanfaatkan oleh masyarakat untuk meningkatkan produktivitasnya.
\end{abstract}

Kata Kunci: pengolahan tanah, mesin penggembur tanah, mesin potong rumput

\begin{abstract}
Soil tillage is an activity that aims to get good soil conditions. Good soil conditions are used as a growing medium for various types of plants and root development. One indicator of a good soil is the level of fertility. Soil fertility is the ability of a soil to provide nutrients for plants. Several processes that can be carried out to maintain soil fertility are soil loosening efforts. Soil loosening is generally done on dry and dense lands and farmers usually still use traditional tools to cultivate the land. The use of traditional tools will certainly reduce the level of productivity because it requires time, effort, and costs that are quite high. Therefore, it is necessary to have tools or machines that can be used to replace these traditional tools. The purpose of this research is to design a soil loosening machine by utilizing a lawn mower as a driving motor. This machine is equipped with a plow and rotary plow. Machine testing was carried out on dry land with an area of $30 \mathrm{~m}^{2}$. Based on the results of research and testing, it is known that a soil loosening machine with a driving motor for a lawn mower has a performance of about $0.115 \mathrm{~m} 2 / \mathrm{second}$ or the equivalent of $414 \mathrm{~m}^{2} /$ hour. The engine performance is still relatively small due to several factors including the small dimensions of the rotary plow and the rotation being too fast. Therefore, there is a need for more optimal modifications and developments so that this machine is expected to be used by the community to increase its productivity.
\end{abstract}

Keywords: tillage, tiller, lawn mower 


\section{PENDAHULUAN}

Tanah merupakan salah satu media yang sangat penting bagi tanaman. Hal ini karena tanah sebagai tempat berkembangnya akar, penyedia unsur hara, dan penyimpan air bagi tanaman. Tanah akan mengalami degradasi jika salah satu fungsi ini hilang (Banuwa, 2013). Untuk menjaga tingkat kesuburan tanah perlu adanya perlakuan dan pengolahan pada tanah tersebut. Pengolahan tanah merupakan suatu kegiatan yang berperan penting dalam kegiatan budidaya pertanian. Kegiatan ini bertujuan untuk mendapatkan kondisi tanah yang baik agar bisa menjadi tempat tumbuh tanaman dan perkembangan akar tanaman. Pengolahan tanah dilakukan dengan menggunakan alat mulai dari yang sederhana dengan memanfaatkan tenaga manusia, seperti cangkul, peralatan yang memanfaatkan tenaga hewan seperti bajak singkal, sampai peralatan yang menggunakan tenaga mesin atau traktor, seperti bajak rotary dan garu (Mardinata \& Zulkifli, 2014).

Pengolahan tanah dapat diklasifikasikan menjadi pengolahan primer dan sekunder. Pengolahan primer berkaitan dengan pengolahan tanah yang lebih dalam dan teliti, dimana umumnya hasil pembajakan memiliki permukaan yang kasar. Adapun pengolahan sekunder berkaitan dengan pengolahan tanah yang dangkal dan selektif sehingga memiliki permukaan yang halus. Pengolahan tanah tipe sekunder biasanya digunakan untuk media penyemaian tanaman. Salah satu pengolahan tanah adalah proses penggemburan. Proses ini bertujuan salah satunya adalah untuk mengembalikan kesuburan tanah (Hermantoro, 2011).

Penggemburan tanah merupakan upaya yang dilakukan untuk mencapai kesuburan tanah. Kesuburan tanah adalah kemampuan suatu tanah untuk menyediakan unsur hara untuk menunjang pertumbuhan tanaman. Proses penggemburan tanah saat ini umumnya hanya mampu menyelesaikan $150-200 \mathrm{~m}^{2}$ per harinya. Untuk menyelesaikan lahan yang luas maka membutuhkan pekerja tambahan sehingga proses penggemburan tanah dapat selesai dengan cepat. Penggunaan peralatan sederhana seperti cangkul, garu, sekop kurang aman untuk petani karena pengoperasian yang manual dan tanpa adanya pelindung terkadang dapat melukai petani. Disamping itu, penggunaan peralatan sederhana juga dapat menyebabkan tingkat kelelahan pekerja meningkat karena kerja otot yang begitu besar dan postur kerja yang tidak ergonomis (Sembiring dkk, 2017). Oleh karena itu, diperlukan alat yang dapat membantu untuk menangani masalah tersebut melalui penerapan teknologi mekanisasi pertanian.

Sesuai dengan defenisinya, mekanisasi pertanian (agriculture mechanization) merupakan penggunaan alat dan mesin pertanian untuk meningkatkan daya kerja manusia dalam proses produksi hasil-hasil pertanian. Penelitian ini bertujuan untuk memodifikasi mesin pemotong rumput tipe gendong sebagai motor penggerak pada alat penggembur tanah yang beroperasi pada lahan kering. Seiring berkembangnya teknologi pertanian dan untuk memenuhi kebutuhan terutama alat bantu petani, maka tak jarang pula banyak produsen mesin pertanian diciptakan, mulai dari kebutuhan mesin kecil hingga mesin-mesin yang besar. Dengan adanya alat ini diharapkan dapat membantu masyarakat terutama petani dalam meningkatkan produktivitas hasil pertanian di lahan kering.

\section{METODE PENELITIAN}

\section{Jenis Penelitain}

Penelitian ini terbagi dalam dua tahapan besar, yaitu pembuatan alat dan pengujian. Pembuatan alat diawali dengan desain dan perancangan, pembuatan komponen-komponen dan fabrikasi. Modifikasi alat ini berkaitan dengan penggunaan mesin pemotong rumput sebagai motor penggerak mesin penggembur tanah. Pengujian alat dilakukan di lahan kering dengan luas lahan tertentu. Tahapan-tahap penelitian dapat dilihat pada Gambar 1.

\section{Alat dan Bahan}

Alat-alat yang digunakan pada penelitian ini antara lain mesin las, gerinda tangan, mesin roll plat, alat penekuk plat, mistar baja, ragum, mesin bor, palu, jangka sorong, dan mistar siku. Adapun bahanbahan yang digunakan adalah besi plat tebal $3 \mathrm{~mm}$, besi plat galvanis, besi siku, pipa 3", pipa 1", dan paku keling.

\section{Desain Mesin Penggembur Tanah}

Mesin ini terdiri dari beberapa komponen dengan memanfaatkan motor penggerak dari mesin potong rumput (Gambar 2). Komponen-komponen pada mesin ini antara lain bodi (kerangka), bajak singkal, roda, bajak rotary, dan motor penggerak. Bajak rotary dapat digunakan untuk pengolahan tanah kering atau tanah sawah. Motor penggerak 
pada mesini ini menggunakan komponen mesin

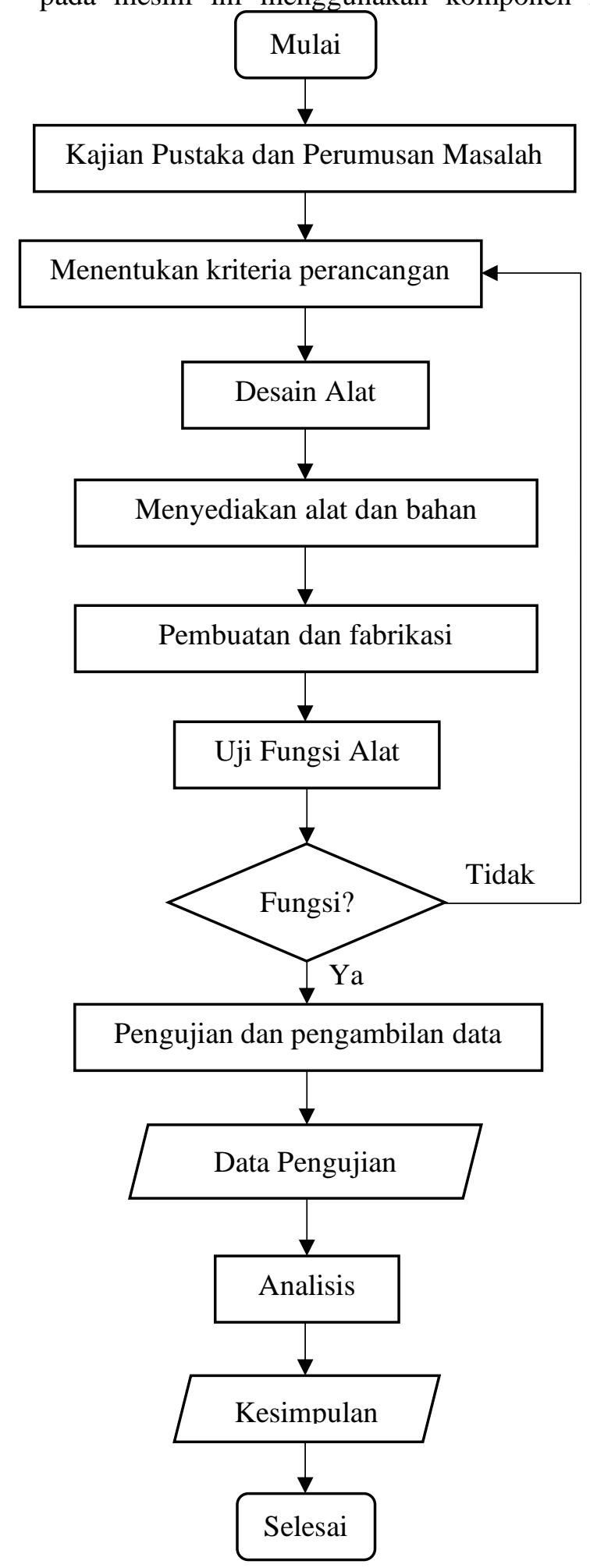

Gambar 1. Diagram Alir Penelitian

pemotong rumput (Gambar 3). Penggunaan mesin ini didasarkan pada kemudahan dalam pengoperasian dan lebih ekonomis. Selain itu, memiliki putaran yang tidak terlalu cepat jika digunakan untuk menggerakkan bajak rotary.

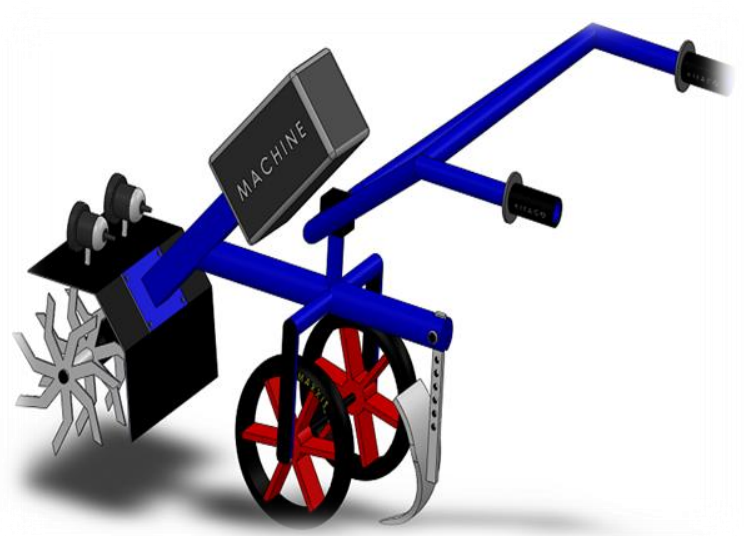

Gambar 2. Desain Mesin Penggembur Tanah

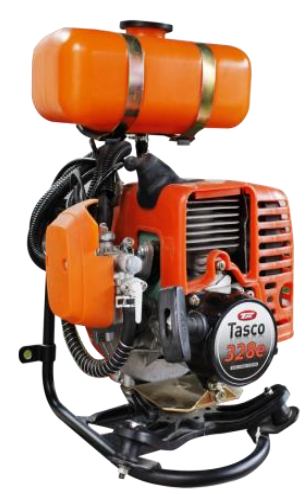

Gambar 3. Mesin Potong Rumput sebagai Motor Penggerak

\section{Analisis Data}

Analisis data dilakukan berdasarkan dua parameter dalam pengujian, yaitu luas lahan (ha) dan kecepatan pekerjaan (m/detik). Parameter yang diukur digunakan untuk menghitung efisiensi kapasitas kerja teoritis (ha/jam) tiap panjang lintasan pengujian atau jarak tempuh mesin.

\section{HASIL DAN PEMBAHASAN}

\section{Desain Alat dan Hasil Pengujian}

Mesin ini dirancang dan dibuat bertujuan untuk menggemburkan tanah, terutama pada lahan kering. Proses ini dilakukan sebagai upaya untuk menjaga kesuburan tanah yang akan ditanami tanaman. Hal ini karena salah satu faktor kesuburan tanah adalah tanah tersebut memiliki struktur yang gembur, tidak keras dan padat. Proses penggemburan tanah 
menggunakan mesin pada penelitian ini (Gambar 4) mampu dijadikan sebagai solusi bagi masyarakat yang selama ini hanya mengandalkan alat-alat tradisional. Meskipun beberapa yang lain sudah menggunakan traktor, tetapi terkendalam dalam biaya operasional. Hasil pengujian dapat dilihat pada Tabel 1.

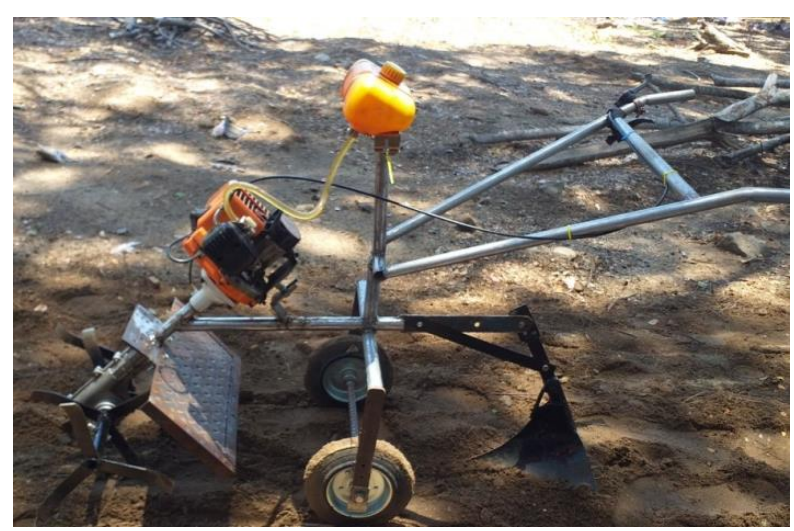

Gambar 4. Mesin Penggembur Tanah

Tabel 1. Hasil Pengujian Kerja Mesin

\begin{tabular}{|c|c|c|c|}
\hline $\mathbf{N}$ & $A\left(\mathbf{m}^{2}\right)$ & $\mathbf{t}(\mathbf{s})$ & $\begin{array}{c}\text { Kinerja } \\
\left(\mathbf{m}^{2} / \mathbf{s}\right)\end{array}$ \\
\hline 1 & 30 & 268 & 0,112 \\
\hline 2 & 30 & 260 & 0,115 \\
\hline 3 & 30 & 257 & 0,117 \\
\hline \multicolumn{2}{|c|}{ Rata-rata } & 261,67 & 0,115 \\
\hline \multicolumn{4}{|l|}{ Ket: } \\
\hline $\mathrm{N}$ & \multicolumn{3}{|c|}{$=$ jumlah pengujian } \\
\hline A & \multicolumn{3}{|c|}{$=$ luasan $\left(\mathrm{m}^{2}\right)$} \\
\hline $\mathrm{t}$ & \multicolumn{3}{|c|}{$=$ lamanya pengujian (s) } \\
\hline
\end{tabular}

\section{Hasil Pengujian}

Berdasarkan Tabel 1 diketahui bahwa semakin cepat waktu pembajakan mengindikasikan bahwa kinerja mesin semakin meningkat. Pada pengujian pertama untuk luas lahan $30 \mathrm{~m}^{2}$ membutuhkan waktu 268 detik, sedangkan pada pengujian kedua dan ketiga masing-masing membutuhkan waktu 260 dan 257 detik. Hal ini menunjukkan bahwa antara waktu pengujian dengan kinerja mesin memiliki hubungan dalam bentuk perbandingan terbalik untuk luas lahan yang. Hubungan tersebut dapat diilustrasikan pada Gambar 5. Berdasarkan Tabel 1 dan Gambar 5 juga dapat disimpilkan bahwa untuk pengerjaan pembajakan penggemburan tanah dengan luas $30 \mathrm{~m}^{2}$ memerlukan waktu sekitar 261,67 detik atau setara dengan 0,073 jam dengan kinerja $0,115 \mathrm{~m}^{2} /$ detik atau setara dengan $414 \mathrm{~m}^{2} / \mathrm{jam}$.
Hasil pengujian menunjukkan tanah tidak sepenuh terbajak. Artinya, kedalaman tanah yang terbajak kecil (Gambar 6). Dengan kapasitas 0,115 $\mathrm{m}^{2} /$ detik menunjukkan kinerja mesin masih kurang baik. Hal ini salah satunya dipengaruhi oleh bajak rotary dan bajak singkal memiliki dimensi yang terlalu kecil mengakibatkan putaran terlau cepat sehingga hasil penggemburan tidak sesuai yang diharapkan. Kapasitas kerja pengoperasian alat atau mesin pertanian tergantung pada tipe dan besarnya alat atau mesin pertanian, keterampilan operator, sumber tenaga tersedia, dan keadaan kerja. Pola pengolahan tanah akan mempengaruhi kapasitas kerja alat pengolah tanah yang digunakan. Pola pengolahan tanah yang baik adalah pola pengolahan tanah yang meminimalisir waktu terbuang. Dalam hal ini, waktu berbelok merupakan waktu yang merugikan, jadi pola pengolahan tanah yang baik adalah pola dengan jumlah berbelok yang paling sedikit.

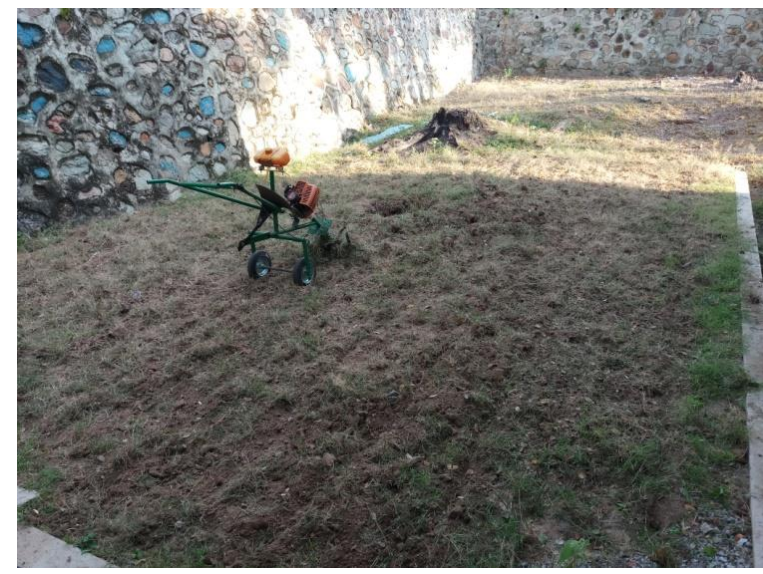

Gambar 6. Hasil Pembajakan

\section{KESIMPULAN}

Berdasarkan hasil penelitian dapat diambil beberapa kseimpulan sebagai berikut:

1. Rancang bangun mesin penggembur tanah dengan memanfaatkan mesin potong rumput sebagai motor penggerak dapat menjadi solusi dalam pengolahan tanah.

2. Mesin penggembur tanah dengan motor penggerak mesin potong rumput memiliki kinerja sekitar $0,115 \mathrm{~m}^{2} /$ detik atau setara dengan $414 \mathrm{~m}^{2} / \mathrm{jam}$.

3. Kinerja mesin masih tergolong kecil karena beberapa faktor diantaranya dimensi bajak rotary yang kecil dan putaran yang terlalu cepat. Sehingga perlu adanya modifikasi dan pengembangan pada komponen ini. 


\section{DAFTAR PUSTAKA}

Banuwa, I. S., (2013), Erosi, Jakarta: Kencana Prenada Media Group

Artawan, G.B.A.B., Tika, I.W., \& Sucipta, N., (2019), Pengolahan Tanah Menggunakan Bajak Singkal Lebih Sedikit Memerlukan Air Irigasi daripada Bajak Rotary, JURNAL BETA (BIOSISTEM DAN TEKNIK PERTANIAN), Vol. 7, No. 1, hal. 120-126.

Hermantoro, (2011), Teknologi Inovatif Irigasi Lahan Kering dan Lahan Basah - Studi Kasus Untuk Tanaman Lada Perdu, Agroteknose, Vol. 5, No. 1, hal. 37-44.

Mardinata, Z., \& Zulkifli., (2014), Analisis Kapasitas Kerja dan Kebutuhan Bahan Bakar Traktor Tangan Berdasarkan Variasi Pola Pengolahan Tanah, Kedalaman Pembajakan dan Kecepatan Kerja, agriTECH, Vol. 34, No. 3, hal. 354-358.

Santosa., Andasuryani, \& Veronica, V., (2005), Kinerja Traktor Tangan Untuk Pengolahan Tanah, Jurnal Teknologi Pertanian Andalas, Vol. 9, No. 2, hal.1-7.

Sembiring, M.T., Wahyuni, D., \& Tarigan, I.R., (2017), Perancangan Alat Penggembur Tanah Untuk Petani Palawija (Studi Kasus pada Desa Kubu Colia Kabupaten Karo), ABDIMAS TALENTA, Vol. 2, No. 1, hal. 32-36. 